\title{
Parameters rationalization for flat double-layer grid spatial structure (STiSK system)
}

\author{
Yevhen Surzhan ${ }^{1 *}$, Kostyantin Rapina ${ }^{1}$, and Tetyana Rapina ${ }^{2}$ \\ ${ }^{1}$ Building Designs Department, O.M. Beketov National University of Urban Economy, 91000, \\ Kharkiv, Ukraine \\ ${ }^{2}$ Building Materials Department, O.M. Beketov National University of Urban Economy, 91000, \\ Kharkiv, Ukraine
}

\begin{abstract}
It is the initial paper in rationalization of steel consumption for flat double-layer grid spatial structure of STiSK system. Brief historical review of metal spatial structures was given. Main economic and production advantages of the system were described Optimal geometry parameters that are satisfied to both ultimate limit and service ability states are offered. Some vital aspects related to the structure BIM design are clarified as well. Results of this research can be used by design engineers, as a basis for geometry determination of STiSk system. Outcomes of the paper can helpful for manufacturers of metal structures as well, and can help them to build up smart life-cycle designs (from engineer's idea to maintenance). BIM process that was presented in this paper will enhance rationalization process of STISK system and opens way for new designs based on this structure. The process can serve as a theoretical basis for full scale tests.
\end{abstract}

\section{Introduction}

Recently, in civilian multistory housing, there has been a significant increase in the use of composite reinforced concrete and steel structural slabs used to construct floors and ceilings [1]. This phenomenon can be explained, apparently by a number of advantages appropriate for such constructions:

- relatively small construction depth of the structure in relation to the span;

- reasonable use of the material (rods work on centric load);

- the possibility of laying engineering networks within the flooring;

- spatial system operations, which makes it possible to span largely without interior supports;

- increased reliability from sudden and progressive damage [2, 3];

- facilitation of roofing enclosure structures due to the frequent grid of nodes;

- maximum unification of nodes and rod elements, that creates conditions for the transition to the continuous manufacture of steel constructions;

- the possibility of using the absolute methods of assembly on the ground and surface lifting in large blocks or in a completely finished form;

- precast-mobility;

\footnotetext{
${ }^{*}$ Corresponding author: EvgenijSurzhan@gmail.com
} 
- architectonic expressiveness and multipurposeness of application for buildings of various purposes.

In the world practice of steel structures constructing, a certain number of classical solutions are known, including: V.A. Kucherenko Central Research Institute of Building Constructions design, "Kislovodsk" and others [4]. Each of mentioned systems has a number of advantages and disadvantages, in connection with which, at the moment there is no wellformed optimal construction solution of the structural design. To the distinctive

complications that arise in the structural constructions design, the following ones can be referred: the complexity of the spatial contacting of the system rod elements; labour intensity of structural construction; ensuring of the joint work of all system elements.

Over the past decade of domestic construction practice, the structural system Structure and Folding (translation of the abbreviation STiSK) [4], developed at Kharkov National University of Municipal Economy, under the supervision of Professor V.S. Shmukler has approved itself. This system has a number of advantages in comparison with the known analogs: small relative height of the structure; relatively low elementary discharge of steel $\left(\mathrm{kg} / \mathrm{m}^{2}\right)$; low labour intensity in production and installation; powerful application capabilities (overlapping span up to $60 \mathrm{~m}$ ). These positive aspects are achieved due to the constructive feature of the system, a detailed description of which can be found in the work [5].

The described system has approved itself well in practice in the construction of objects for various purposes in the city of Kharkov (Figure 1).

On the basis of the above mentioned information, it comes that the issue of the described system research for possible minimization of its own weight, as well as searching for possible constructive improvements in the folded structure, is very relevant in the view of the positive implementation of the Structure and Folding (STiSK) system in design and construction practice.

a)

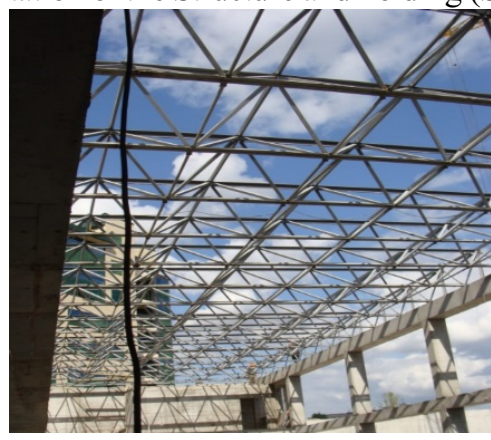

c)

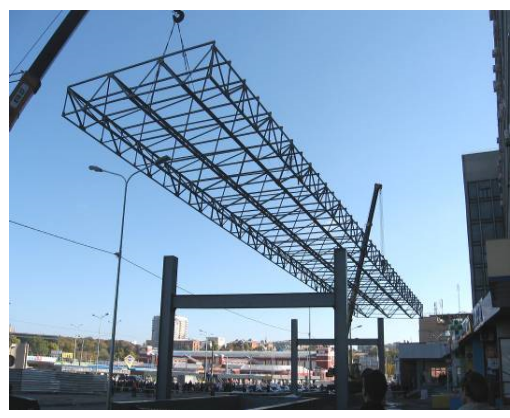

b)
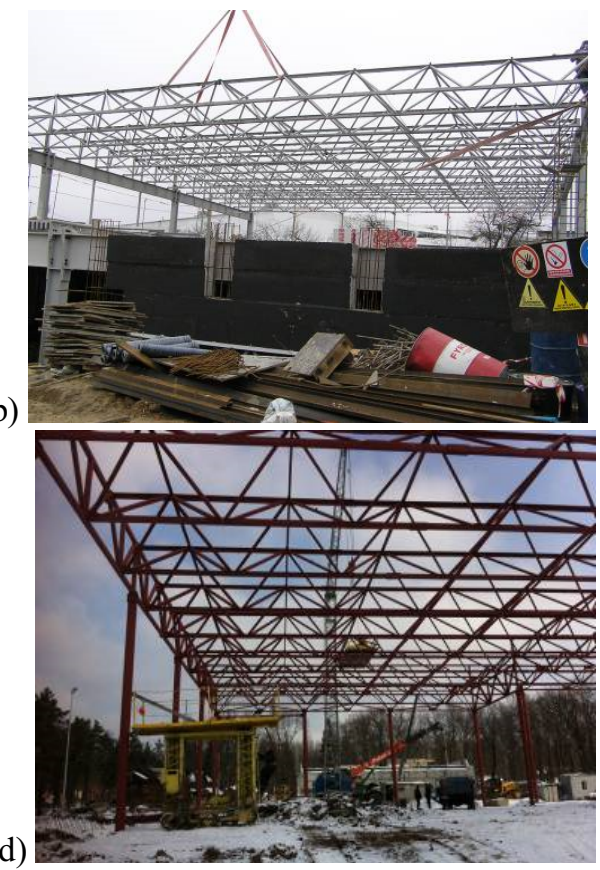

Fig. 1. Examples of application of the Structure (STiSK system):a- Misto swimming basin; bconfectionery shop; c- metro station Tsentralnyi Rynok entrance canopy;d- children's entertainment center.

The purpose of this study is to find possible ways of steel consumption minimization $\left(\mathrm{kg} / \mathrm{m}^{2}\right)$ in the fold. 
The object of the study is the coating of the structural Structure and Folding (STiSK) system.

The subject of the study is the parameters that affect the steel consumption of the chords of the research object.

The intended purpose of the research can be achieved by a numerical analysis of the system operation in two groups of limit states. The most common system spans in the design practice (from $18 \mathrm{~m}$ to $40 \mathrm{~m}$ ) were accepted for analysis, with relative construction heights from $1 / 10$ to $1 / 30$. As a result, the dependence of the steel consumption on the relative heights of the structure cross section should be obtained for each span. At the same time, the criterion for a minimum of the system's own weight is the analytical point of steel consumption intercrossing in the ultimate and service limit states, that theoretically, makes it possible to use the construction material most effectively.

As simplifying conditions, the following are accepted:

- The model for work analyzing of the fold is accepted as a basic structural component, formed by two trusses (a modular element).

- It is assumed that the chords of the truss work together (the compliance of the braces is not taken into account).

- The angle of braces slope in the modular element is conventionally adopted as close to the optimal value [5].

- The angle of truss slope to each other is constantly 45 degrees (due to the design features of the system).

- The external load distributed uniformly defaults to the node load.

- When calculating in the ultimate limit state, the chords section is taken from a square tube with a constant wall thickness $(4 \mathrm{~mm})$ and a variable section height.

- When calculating the service limit state, the section of the chords is taken in the form of continuous squares (Figure 2).

\section{Calculating in the service limit state}

The calculation of the limit deformations is made on the assumption of the normatively limited permitted values of the deflections of such structures. In this case, the permitted deflection is accepted:

$$
\mathrm{f}_{\max }=\frac{1}{200} * \mathrm{l}
$$

Substituting the restriction $(1)$ into the expression for the maximum deflection of a pinended beam, we will obtain:

$$
\frac{1000}{384} \frac{\mathrm{ql}^{3}}{\mathrm{EI}_{\mathrm{X}}}=1
$$

Further, from (2) we will express the fold moment of inertia, at which the system deflection volume will be equal to (1):

$$
I_{x}=\frac{1000 q l^{3}}{384 E}
$$

Taking into account the accepted simplifications, we will write the expression of the moment of inertia of a section of the fold (Fig. 2):

$$
I_{x}=4\left[\frac{b^{4}}{12}+b^{2}\left(\frac{h-b}{2}\right)^{2}\right]=b^{4}-2 b^{3} h+b^{2} h^{2}
$$




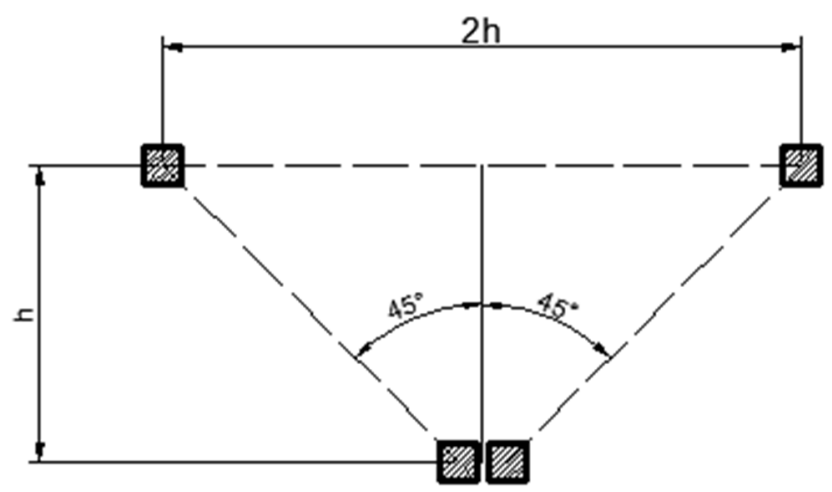

Fig. 2. Cross section of the fold.

Substituting (3) into (4) we will obtain:

$$
b^{4}-2 h b^{3}+h^{2} b^{2}-\frac{1000 q l^{3}}{384 E}=0
$$

Solving (5) in general form, it can be noted that this equation has two real roots, one of which is suitable in the physical sense of the task [5]:

$$
b=\frac{1}{2}\left(h+\sqrt{h^{2}-4 \sqrt{\frac{1000 q l^{3}}{384 E}}}\right)
$$

The obtained solution (5) allows us to determine the minimum permitted (according to the service limit state) required cross-sectional area of chords of the Structure and Folding (STiSK) system in relation to the span of the structure $(l)$, the external load $(q)$ and the adopted system altitude $(h)$. For visual illustration of the working efficiency of this approach, a numerical solution analysis ( 6 ) was performed. Having set the external load distributed uniformly $\left(q=500 \mathrm{~kg} / \mathrm{m}^{2}\right)$, the steel consumption for the structure for spans of $18,24,30$, 36,40 meters is determined, depending on the height of the structural system.

\section{Calculating in the ultimate limit state}

When calculating in the ultimate limit state, the chords of the trusses were calculated as centrally compressed rods in accordance with [7]:

$$
\frac{N * \gamma_{n}}{\varphi * A * R y^{*} \gamma_{c}} \leq 1,
$$

where $\varphi$ is the stability coefficient under central compression, which value at $\lambda \geq 0.4$ is to be calculated according to the formula:

$$
\varphi=\frac{0.5}{\bar{\lambda}^{2}}\left(\delta-\sqrt{\delta^{2}-39.48 \bar{\lambda}^{2}}\right),
$$

where $\bar{\lambda}$ is conventional flexibility.

The value of the coefficient $\delta$ should be calculated according to the formula:

$$
\delta=9.87(1-\propto+\beta * \bar{\lambda})+\bar{\lambda}^{2},
$$


where $\alpha$ and $\beta$ are the coefficients characterizing the initial imperfections and residual intensions and are determined in accordance with [7] (for the considered example $\alpha=0.03$, $\beta=0.06$ ).

Having been given with the initial data, analogous to the calculation in the service limit state, the steel consumption for the system under research is determined, depending on the

height of the structure and the span, based on the limitations of the material strength. The calculation was carried out by successively iterating of the buckling coefficient $\varphi$, while the convergence was determined from the condition of the difference between the steps of iteration $\leq 1 \%$.

Taking into account the adopted simplifications, in this calculation the length of the rods of the compression chord of the fold depended only on the altitude of the structure, and the radius of cross of the rods at each step was determined from the required design altitude of the square tube in the previous step.

On the basis of the obtained data, diagrams of the dependence of material consumption on the structural Structure and Folding (STiSK) system depending on the height of the structure for spans of $18 \ldots 40 \mathrm{~m}$ are shown Fig. 3, 4. From the data in the diagrams, it comes that without significant influence from the span, the material consumption functions on the system chords along different limit states intersect in the system height range 1/20 - 1/21.

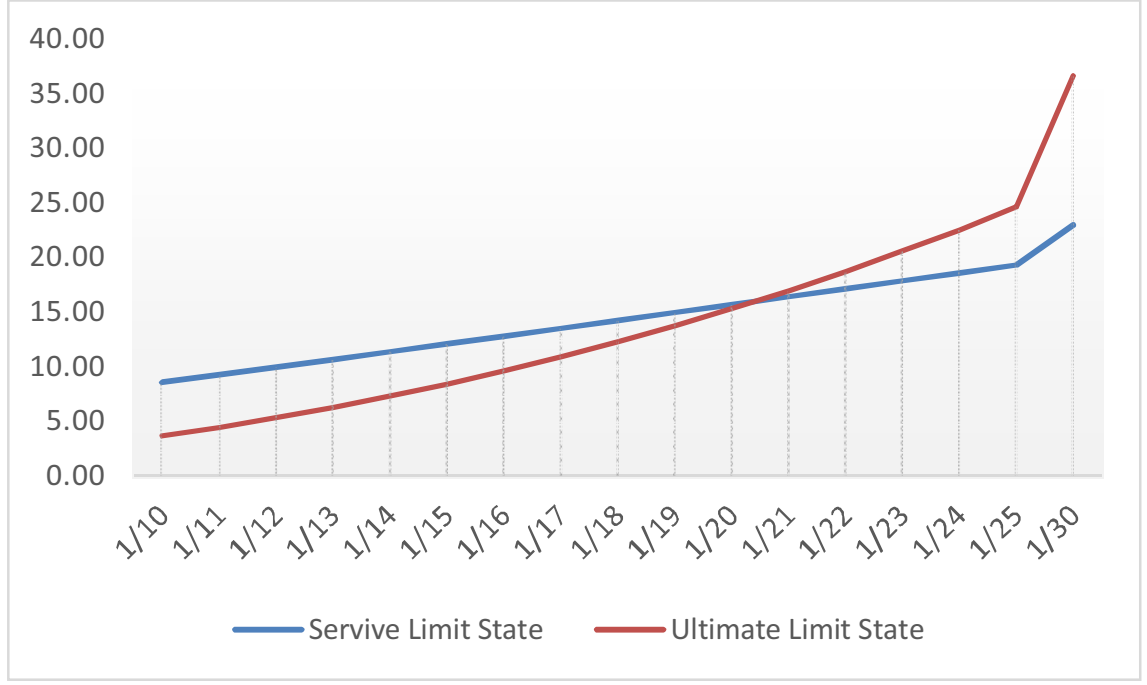

Fig. 3. Steel consumption $\mathrm{kg} / \mathrm{m}^{2}$ for the span $18 \mathrm{~m}$.

\section{Verification}

To confirm the obtained theoretical results, it is necessary to perform verification calculation of structures using FEM. The difficulty in this case is the creation of numerous computational schemes when varying geometric parameters.

The geometry of the structure depends on a number of parameters. To determine them, it is needed to understand the logic of structural construction. Thus, in the Structure and Folding (STiSK) system, the modular element (truss) (Fig. 5) forms the basic structural element (Fig. 6 ), by connecting the former at an angle of $45^{\circ}$. In its turn, the structural plate body is enlarged from the structural elements in the transverse direction.

Among which the defining ones are the span of the structure, its construction height, as well as the angle of slope of the rods in the modular elements. (Fig. 5.) The structure is formed 
from the basic structural components, which in their turn form a complete structure with the necessary dimensions.

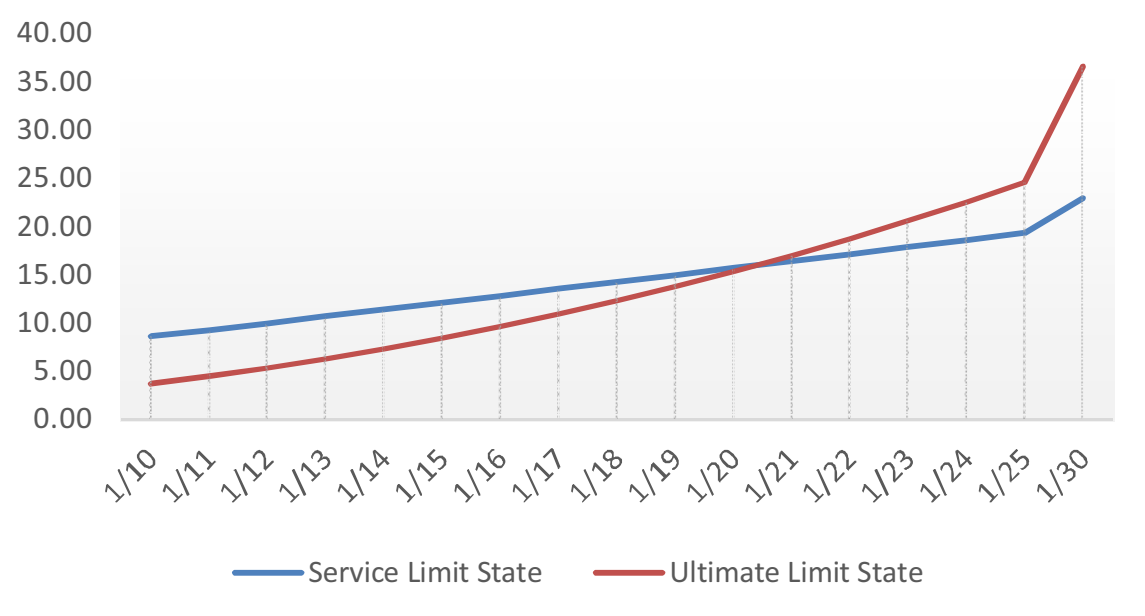

Fig. 4. Steel consumption $\mathrm{kg} / \mathrm{m}^{2}$ for the span $40 \mathrm{~m}$.

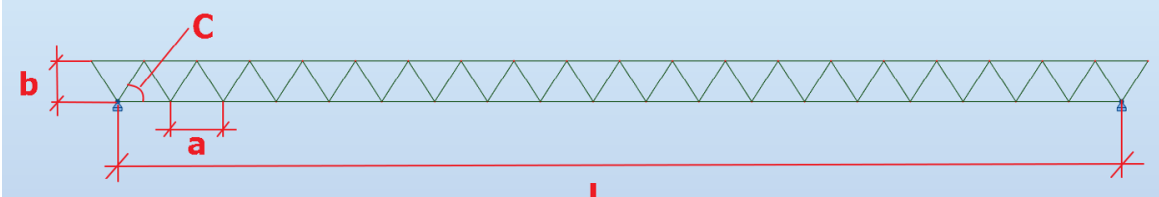

$\mathbf{L}$

Fig.5. Truss, modular element. $a$ - spacing of nodes, $b$-truss height on the support, $c$ - the angle of slope of the rods in the truss and $L$ - truss span.

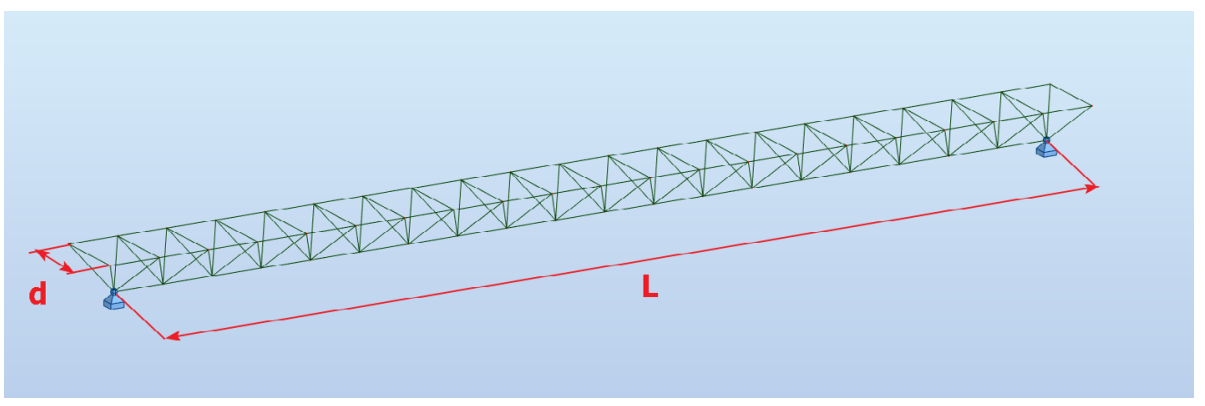

Fig. 6. General view of the basic structural component. $d$-width of the modular element.

Thus, the main benchmark data determining the outer look of the structure is the parameters of the truss. This is primarily the span of the structure $(L)$, depending on which the construction height of the future structure is assigned. It lies in the range from 1/10-1/30 of the main span.

It should be noted that the reducing of the height of the structure, that is not used directly, reduces the cost of building operation. Therefore, structures with the minimum possible height are of particular interest [8].

The angle of slope of the rods in the trusses is taken on the basis of the optimal material consumption [5], and lies within the range. The datum angle is assumed to be $65^{\circ}$. Then, the 
spacing of nodes in the truss $(a)$ is calculated, as well as the number of steps in the truss. The obtained number is rounded up to a nearest whole number and the angle of slope of the rods is recalculated. The angle is checked for compliance with the criterion of optimal material consumption. If it was, then the calculation is continued, otherwise the number of panels changes to match the criterion of the angle of slope of the rods.

Concerning the width of the basic structural components " $d$ " in the transverse direction, it depends on the angle of the trusses slope in this direction. Inasmuch as the angle is constant $\left(45^{\circ}\right)$ and is determined by design considerations, the width is always equal to the height of the truss on the support defining the geometry, according to the initial structure parameters $(d$ and $L$ ). This algorithm was used to write the program in Dynamo 1.3.0 and for creating the calculation schemes for Autodesk Robot Structural Analysis. Also, the possibility of creating a BIM model for Autodesk Revit was carried out for the purpose of node detailing and connections in Autodesk Advance Steel or Teckla Structure to simplify the process of real design of structures.

Further, the obtained calculated schemes were calculated with the parameters obtained during the research. Noteworthy, that the initial assumptions and the obtained results can be correctly compared only for a number of parameters, such as the cross-sectional area of the chords and lattice profiles, the ultimate deflections of the structure. For each span, the construction height was chosen, the value of which was obtained as an analytical intersection of the two steel consumption curves for the service and ultimate limit states.

The sections of the chords were assigned from paired angles, and the lattices were assigned from the square tubes. At the same time, the area of the section of the chords corresponded to calculated ones as close as possible. Noteworthy, that those rolled sections were applied that are rollable outside Ukraine.

\section{Conclusion}

The results of the calculation showed that the results of the calculations given in the first part of the article are confirmed with a high degree of probability. Especially constructions with construction depths, defined earlier, satisfy both limit states and are approximated to the minimum material consumption. But it should also be noted that further study of this issue is necessary, taking into account the rods of the lattice of the trusses, and the runs along the upper and lower chords of Structure and Folding (STiSK). It is also worth mentioning that significant change of the obtained results is possible when binding to domestic rolled steel products, which also requires additional research. It is noted that the obtained data in the work shows the possibility of work simplification of the Structure and Folding (STiSK) system, which for today is seemed to be a very priority and topical direction, taking into account wide interest in this construction in the field of design and building.

\section{References}

1. S.S. De Silva, D.P. Thambiratnam, Computers \& Structures, 87(17), 1067-1076 (2009)

2. Y. Ding, W. LIN, Z. LI, Engineering Mechanics, 3, 97-101, (2007)

3. Y.Alashker, S. El-Tawil, F. Sadek, Journal of Structural Engineering, 10, 1187-1196 (2010)

4. V.S. Shmukler, N.P. Burak, A.I. Duker, I. Vassim, patent of Ukraine 84560

5. V.S. Shmukler, E.V. Berezhnaya, V.V. Gerasimenko, O.A. Kalmikov, V. Ismail, Vestnik KhNADU, 49, 75-83 (2010)

6. DSTU B V.1.2-3:2006. Progini ta peremishennya. Vimogi proektuvannya, Kiev (2006)

7. DBN B V 2.6-198:2014. Stalevi konstruktsii. Normi proektuvannya, Kiev (2014)

8. J. Kneifel, Energ Buildings, 3, 333-340 (2010) 